\title{
Study on Case Teaching Methods in Applied Statistic Course for the Ability of Application
}

\author{
Xiang $\mathrm{Jia}^{1, \mathrm{a},{ }^{*}}$ and Xiaoyue $\mathrm{Wu}^{1, \mathrm{~b}}$ \\ ${ }^{1}$ College of Systems Engineering, National University of Defense Technology, Changsha, Hunan, P.R.China \\ aiaxiang09@sina.cn, ${ }^{b}$ xiaoyuewu@vip.163.com \\ *Corresponding author
}

\begin{abstract}
The applied statistic course is basic for statistic as well as management science and engineering specialties. With the development of Big Data and Artificial Intelligence, together with the guidance of by Ministry of Education, there are new requirements for this course. We conduct the study on case teaching in the applied statistic course reform for management science and engineering specialty and apply it to the course teaching. First, the necessity of case teaching is stressed. Next, the basic rules for the cases are pointed out. Further, the methods for the case teaching are designed. Finally, the study is assessed by the application in course teaching. It shows that the case teaching improves the training of statistic thought and ability of application for students.
\end{abstract}

Keywords: applied statistic, case teaching, ability of application

\section{面向应用能力的《应用统计学》课程案例教学方法研究}

\author{
贾祥 ${ }^{1, a, *}$, 武小悦 ${ }^{1, b}$
}

\author{
${ }^{1}$ 系统工程学院, 国防科技大学, 长沙, 湖南, 中国 \\ ajiaxiang09@sina.cn, ${ }^{b}$ xiaoyuewu@vip.163.com \\ *通讯作者
}

\section{摘要}

《应用统计学》是统计类和管理科学与工程专业的重要基础课程。大数据和人工智能时代的来临, 以 及全国范围内金课建设的指引，对该课程的建设提出了新的要求。我们针对管理科学与工程专业的《应 用统计学》课程教学改革问题, 开展了案例教学研究, 并依托具体的教学任务进行了实践。本文首先 论述了案例教学的必要性, 其次指出了案例编写的若干原则, 随后提出了案例教学设计的流程方法, 最后结合具体案例教学实践的效果对案例研究进行了检验。总体来看, 我们所开展的案例教学改革支 撑了学员统计思维的培养和应用能力的提高。

关键词: 应用统计学, 案例教学, 应用能力

\section{1. 引言}

随着社会和科技的发展, 大数据和人工智能技术如火如 茶。2015 年 8 月国务院印发了《促进大数据发展行动纲 要》, 着力强调了 “加强专业人才培养”, 鼓励高校设立 数据科学和数据工程相关专业, 大力培养具有统计分析、 计算机技术、经济管理等多学科知识的跨界复合型人才 [1]。这对统计类专业和课程的建设提出了新的要求, 也 带来了新的机遇。

本科教育作为国民教育的重要组成部分, 越来越受到国家 的重视。教育部部长陈宝生在出席新时代全国高等学校本 科教育工作会议上指出要全面推进 “四个回归” ，即回归 常识: 学生要刻苦读书; 回归本分: 老师要潜心教书育人; 回归初心: 高校要培养建设者和接班人; 回归梦想: 要实 现教育报国梦、强国梦。在第十一届 “中国大学教学论坛” 上, 教育部高等教育司吴岩司长提出了 “两性一度” 的“金
课” 标准: 高阶性、创新性、挑战度。《应用统计学》课 程作为统计类专业和管理科学与工程专业的重要基础课 程, 如何在大数据时代来临和金课建设的引导下进行该课 程的教学改革, 是亟需研究的重要课题。本文旨在从案例 教学的视角, 以国防科技大学管理科学与工程专业《应用 统计学》课程为例, 探讨新形势下该课程的教学改革。

\section{2. 《应用统计学》案例教学方法研究}

\section{1. 案例教学的必要性}

《应用统计学》课程是一门实践性和应用性很强的课程, 在该课程的第一节课上,授课教师往往会讲述统计学广泛 的应用领域[2]，但在后续的统计方法教学中，却又变成 “教师讲授一学生听讲一课后作业”的学生被动接受式教 
实际问题, 这样才能保证案例教学中的师生互动和讨论效 果。

（5）综合性。案例教学中的案例应涉及到较多的统计理 论概念和方法,这样可以运用一个案例讲授和讨论较多的 统计理论方法, 提高案例教学的效果。

我们在开展案例教学实践前, 依据上述原则, 编写形成了 案例集。

\section{3. 案例教学设计}

依托编写的案例集，按照下述流程方法开展案例教学设 计。

首先, 结合每节课的教学目标和任务, 从案例集中选择恰 当的案例用于本节课的案例教学, 所选择的案例应包含本 节课所要求掌握的统计概念和理论方法。在此基础上, 应 对所选的案例进行精心的准备, 设计出可以讨论的问题、 与相关统计概念有关的对象, 以及应用本节课所要求掌握 的理论方法进行求解后所得的结果。如有必要, 也可以在 课前将整理好的案例集发给学员, 引导他们结合授课内容 进行预习。

其次, 在课堂教学的开始环节中,介绍案例的背景和问题, 要求学员思考如何解决案例中的实际问题, 组织学员进行 讨论。此时, 授课教师应对学员的回答进行点评, 要指出 学员所回答的解答方式有何优劣。当学员的解答方式不能 满足案例中实际问题的需求时, 教师应给出明确的具体原 因, 启发学员认识到现有方法的不足。而当学员的回答能 够在一定程度上解决案例中的实际问题, 教师应给予积极 的肯定, 激发学员的信心, 鼓励学员在后续继续参与讨论。 通过理论授课前的讨论, 可以改善课堂的教学氛围, 调动 学员学习的兴趣, 吸引学员带着问题进入到后续的理论授 课中去。

随后, 开始讲授本节课所要求掌握的统计理论方法, 可用 于解决案例中的实际问题。在具体讲授中, 要结合案例实 际问题突出理论重点。为了将案例教学贯穿课堂始终, 在 讲授相关统计概念时, 应结合案例中的具体对象进行阐 述, 既可使得抽象的统计概念具体化、直观化、客观化 [7], 加深学员对所学知识的理解, 又重新调动了学员在课堂开 始环节中的案例讨论内容, 保证了学员的学习兴趣。

接着, 在讲授完本节课所要求的统计理论方法后, 应再次 回到案例实际问题中, 组织学员应用新学习的统计方法对 案例实际问题进行解答, 并分析实际问题的求解结果。在 这个过程中, 教师应适时引导, 对其中暴露出的错误认识 进行纠正, 对理解不到位的概念进行强调, 同时结合学员 的分析解答, 向学员展示如何操作常用的 SPSS 等统计软 件来求解实际问题的过程, 从而在案例教学中穿插了实践 操作能力的培养。

最后, 教师应对整节课的讨论、讲授和分析进行总结, 也 可视情对比新学习的统计理论和已学习的统计方法在适 用性上的差异, 从而加深对案例实际问题应用分析的理 解, 培养学员的统计思维和应用能力。

在根据以上内容开展案例教学方法设计时, 应特别注意以 下几个问题:

（1）在每节课的案例整理和准备时, 要考虑案例与课程 教学目标和内容的契合度, 还要考虑案例与学员知识水平 的匹配性, 最好挑选与学员现有知识结构相匹配的信息适

(4) 发散性。案例教学中的案例不应有唯一的标准答案, 只要假设成立, 方法得到, 分析合理, 就能解决案例中的 
要基础课程。大数据和人工智能时代的来临, 以及全国范 围内金课建设的指引，对该课程的建设提出了新的要求。 我们针对管理科学与工程专业的《应用统计学》课程教学 改革问题, 开展了案例教学研究, 并依托具体的教学任务 进行了实践。本文从案例教学的必要性、案例编写、案例 教学设计和案例教学效果等方面论述和总结了我们的案 例教学研究工作。总体来看, 案例教学研究的方向是正确 的, 效果也是明显的, 后续我们将持续开展案例教学研究 的深化工作。

\section{致谢}

本文为 2019 年度湖南省普通高等学校教学改革研究项目 《面向应用型人才的军队院校应用统计学课程教学改革 与实践》和 2019 年度国防科技大学系统工程学院教育教 学改革研究重点课题《面向任职岗位能力的《应用统计学》 军事背景案例教学研究》的阶段性成果之一。

\section{参考文献}

[1] 齐立美. 大数据背景下应用统计学专业建设的教学探 讨-一以塔里木大学为例 [J]. 教育教学论坛, 2019(17): 65-67.

[2] 薛艳. 应用统计学课程教学改革的探讨-一基于 389 名学生的调查分析 [J]. 临沂大学学报, 2013, 35(6): 83-85.

[3] 招莉莉, 唐国芬. 基于 CDIO 理念的应用统计学课程 教学改革探索 [J]. 教育观察, 2016, 5(9): 83-84.

[4] 姜粀朋经济类专业 “应用统计学” 课程案例教学法 探析 [J]. 中国管理信息化, 2015(7): 245-246.

[5] 黄海军, 王国强, 张涛. 依托案例的应用统计学专业 教学方法初探 [J]. 高教学刊, 2019(3): 81-82+85.

[6] 孙薇, 王锋. 案例教学在高校数理统计课程中的必要 性研究 [J]. 当代教育实践与教学研究, 2016(7): 24.

[7] 刘宇, 韩雪, 张一昕. 案例教学在中医药课程中的应 用与分析 [J]. 教育教学论坛, 2018(6): 182-184.

[8] 熊立, 伍婷婷, 凌玉婷. 基于实践能力培养的创新创 业课程案例教学设计研究 [J]. 教育教学论坛, 2019(4): 149-150.

[9] 范永茂. 公共管理硕士全案例教学实践研究——中国 人民大学 MPA 培养经验与思考 [J]. 教育理论与实践, 2019, 39(9): 12-14.

《应用统计学》课程是统计类和管理科学与工程专业的重 